\title{
RELATIONSHIP BETWEEN STUTTERING SEVERITY AND DEMOGRAPHIC CHARACTERISTICS IN CHILDREN WHO STUTTER OF AGE RANGE 6.5 TO 9.5 YEARS CONCERNING THEIR AGE, GENDER AND MENTAL CAPABILITIES
}

\author{
Aya Sayed Ahmed Nasr**, Mona Abdel-Fattah Hegazi*, \\ Fatma El-Zahraa Abdel-Hamid Kaddah*, Hedia Muhey El-Deen Ahmed*
}

\footnotetext{
* Unit of Phoniatrics Otorhinolaryngology Department, Faculty of Medicine, Ain Shams University, Cairo, Egypt.

** Unit of Phoniatrics -

Otorhinolaryngology Department, Minya Al-Qamh General Hospital, Egypt.

Corresponding author Aya Sayed Ahmed Nasr Mobile: (+2) 01289175537

E.mail:

Dawn.Smile92@yahoo.com.

Received: $15 / 7 / 2021$

Accepted: 11/8/2021
}

Online ISSN: 2735-3540

\begin{abstract}
:
Background: Stuttering is the most common fluency disorder in which there is a disruption in the forward flow of speech in form of (repetitions, prolongations, blocks, interjections, revisions) and may be accompanied by secondary behaviors, physical tension, negative reactions, increased avoidance, or decreased overall communication.

Related to the lack of a single cause to stuttering is the fact that there are a number of factors that place an individual at increased risk of developing the disorder. Age, gender and mental capabilities represent important risk factors of stuttering and also may play a role in increasing stuttering severity.
\end{abstract}

Aim of the Work: This study aims at investigating the association between stuttering severity of children who stutter and their age, gender and mental capabilities. These factors are important for the initial assessment of stuttering and may be useful for establishing what intervention is appropriate.

Patients and Methods: An exploratory study. Sample size included 30 children of age range 6.5 to 9.5 years with fluency disorders. All of them underwent psychometric evaluation by using Stanford-Binet Intelligence Scale $4^{\text {th }}$ edition and assessment of stuttering severity by using Stuttering severity instrument-Arabic form (SSI-Arabic form).

Results: Revealed that there were negative correlations, though non-significant, between SSI scores and age of the studied group as a whole $(r=-0.07)$. The correlations between IQ and SSI scores for the main group as well as both male and female groups were negative with no statistically significant findings $(r=-0.29,-0.29,-0.012$, respectively). There were no statistically significant differences between SSI scores in males and females $(P$-value $=0.43)$.

Conclusion and recommendation: In the age range of 6.5 to 9.5 years, the male to female ratio of stuttering was 3.2:1. Speech dysfluencies as measured by SSI tends to decrease as the child's age increases and as IQ level increases within the average category of IQ. However, such relations are not statistically significant.

Keywords:

Stuttering severity, age, gender, an intelligence quotient (IQ)

\section{INTRODUCTION}

Fluency is the aspect of speech production that refers to continuity, smoothness, rate, and effort. Fluency disorders are characterized by deviations in continuity, rhythm, smoothness, or effort in speech. Stuttering is the most common 
fluency disorder characterized by disruption in the forward flow of speech in form of (repetitions, prolongations, blocks, interjections, revisions) and may be accompanied by secondary behaviors, physical tension, negative reactions, increased avoidance, or decreased overall communication $^{(\mathbf{1})}$.

Stuttering is one of the most common developmental disorders and affects approximately 1-2 \% of the population ${ }^{(2)}$. According to ${ }^{(3)}$ and ${ }^{(4)}$, it has an incidence of around $5 \%$ in the pre-school population, while according to ${ }^{(5)}$, it has a rate of $9 \%$. Stuttering is most common in children, and usually begins in early childhood between two and five years of age ${ }^{(6)}$. Stuttering usually begins around the time children start forming simple sentences ${ }^{(7)}$. However, a few children do not begin to stutter until as late as age seven or even later ${ }^{(8)}$.

There are a number of factors that place an individual at increased risk of developing Stuttering ${ }^{(9)}$. Various environmental and personal factors were shown to interact with the children who stutter (CWS). Environmental factors, include, for example, culture $^{(\mathbf{1 0})}$, school or social settings ${ }^{(11)}$ and work setting ${ }^{(\mathbf{1 2})}$. Personal factors may include a wide range of characteristics. Apparently, the most commonly examined factors were temperament, personality trait and personal beliefs ${ }^{(\mathbf{1 3})}$. Nonetheless, the potential effect of basic personal factors, such as age, gender and mental status on the individual's experience of stuttering have only been discussed limitedly ${ }^{(\mathbf{1 4})}$.

The actual incidence of stuttering before the age of six years is much higher than the later years $^{(\mathbf{1 5})}$.

Manson $^{(3)}$ found that the incidence of stuttering reached the level of $5.19 \%$ at the age of 2 years. Out of these children, $71.4 \%$ stopped stuttering within 2 years .The incidence of stuttering ranges from $2.1 \%$ in adults (21-50 years) to $2.8 \%$ in younger children (2-5 years) and $2.4 \%$ in older children (6-10 years) ${ }^{(\mathbf{1 6})}$.

In Egypt Abou El-Oyoun ${ }^{(17)}$ reported that the prevalence of stuttering was 0.29:0.55\% in both urban and rural areas in the Upper Egypt. Abou Ella et al. ${ }^{(\mathbf{1 8})}$ stated that the prevalence of stuttering among primary school children in Cairo was $1.03 \%$.

Research studies report consistently that stuttering affects boys more often than it does girls. Reported male/female ratios in early childhood range from $1.6: 1$ to $2: 1$ in children aged 2 to 5 years. In older children, the ratio reported is higher still at around 5.3:1 and 4:1 ${ }^{(6)}$.

Models of stuttering often incorporate cognitive elements ${ }^{(\mathbf{1 9})}$, yet broad testing of intelligence has not been investigated in groups of young CWS.

In our study, we assess relationship between stuttering severity and demographic characteristics of children who stutter regarding their age, gender and mental capabilities. These factors could reasonably be argued to be potential risk factors in the identification of stuttering.

\section{AIM OF THE WORK:}

This study aims at investigating the association between stuttering severity of CWS and their age, gender and mental capabilities.

\section{PATIENTS AND METHODS:}

This study was an observational cross sectional (Exploratory) study. It was carried out at the Phoniatrics Unit, Otorhinolaryngology Department, Faculty of Medicine, at Ain Shams University Hospitals. The study started in January 2020 and ended in March 2021. Sample size included 30 children with fluency disorders. Their age ranged between 6.5 to 9.5 years. For the sake of statistical analysis, they were 
divided into 3 subgroups according to age. Subgroup (I): With age range of 6 years \& 6 months to 7 years \& 5 months. Subgroup (II): With age range of 7 years \& 6 months to 8 years \& 5 months. Subgroup (III): With age range of 8 years $\& 6$ months to 9 years \& 6 months. All of them underwent psychometric evaluation by using StanfordBinet Intelligence Scale 4th edition ${ }^{\mathbf{( 2 0})}$ and assessment of stuttering severity by using Stuttering severity instrument-Arabic form (SSI-Arabic form) $^{(21)}$.

The sample of children was selected upon the following inclusion and exclusion criteria.

\section{Inclusion criteria:}

1. Children with fluency disorders.

2. Children's age ranged between 6.5 to 9.5 years.

\section{Exclusion criteria:}

1. Children with any neurological disorders.

2. Children with hearing Impairment (HI), visual, cognitive or motoric problem.

\section{Ethical considerations:}

All parents of children involved in this study provided their informed consents. The study protocol was approved by the Ain Shams University Ethical Committee of Human Research.

\section{Methods:}

All children of the study were subjected to the protocol of assessment of fluency disorders which is applied at the Phoniatrics
Unit, at Ain Shams University Hospitals ${ }^{(20)}$. It includes the following items:

\section{Elementary diagnostic procedures:}

A. Patient parent interview: History talking and complaint.

B. Auditory perceptual assessment of speech.

\section{Examination.}

\section{Clinical diagnostic Aids:}

A. Augmentation and documentation of auditory perceptual assessment: Speech recording using recorder of mobile Samsung Galaxy J4+.

\section{B. Formal testing:}

1. Assessment of stuttering severity: By using Stuttering severity instrumentArabic form (SSI-Arabic form) ${ }^{(21)}$.

2. Psychometric evaluation: StanfordBinet Intelligence Scale, 4th edition, to provide the intelligence quotient (IQ) and the mental age ${ }^{(22)}$.

\section{Data Analysis:}

Data were tabulated and statistically analyzed using The Statistical Package for Social Sciences (SPSS), version 20 (SPSS Inc., Chicago, IL). Descriptive statistics were done for quantitative data as mean \pm SD (Standard Deviation), and ranges for quantitative data, while numbers and percentages for qualitative data. Pearson correlation was used as well as ANOVA test for studying the effects of the studied variables on stuttering severity (SS).

\section{RESULTS:}

Table (1): Distribution of children's characteristics in the study group $(n=30)$

\begin{tabular}{|l|l|c|}
\hline \multicolumn{2}{|l|}{} & Mean \pm SD (Min - Max) \\
\hline \multicolumn{2}{|l|}{ Chronological age (months) } & $90.8 \pm 12.1(78-113)$ \\
\hline \multirow{2}{*}{ Gender } & Male & N $(\%)$ \\
\cline { 2 - 3 } & Female & $23(76.7 \%)$ \\
\hline
\end{tabular}

The chronological age range was 6.5 to 9.5 years with Mean \pm SD $(90.8 \pm 12.1)$. Male children represented $77 \%$ of the study group, while female children represented $23 \%$ of the study group (Table 1, Diagram 1). 


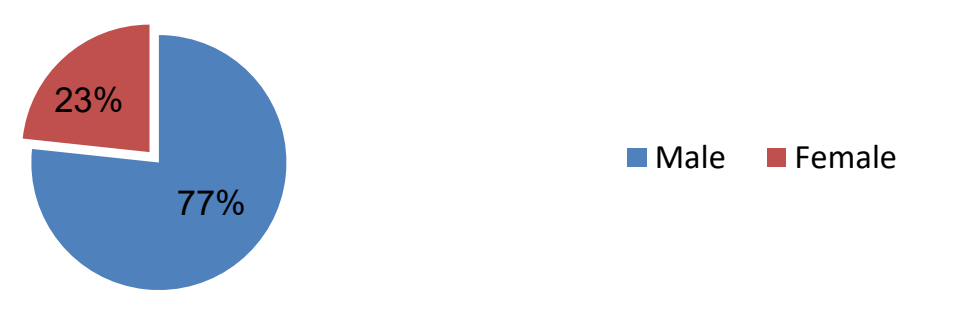

Diagram (1): Gender distribution of the study group

Table (2): Distribution of SSI and IQ test results among the study group

\begin{tabular}{|c|c|c|}
\hline & Mean \pm SD $($ Min - Max $)$ \\
\hline \multicolumn{2}{|l|}{ IQ } & $94.2 \pm 1.8(92-98)$ \\
\hline \multicolumn{2}{|l|}{ SSI score } & $25.7 \pm 4.5(20-33)$ \\
\hline & & $\mathrm{N}(\%)$ \\
\hline \multirow[t]{3}{*}{ SSI degree } & Mild & $10(33.3 \%)$ \\
\hline & Moderate & $14(46.7 \%)$ \\
\hline & Severe & $6(20 \%)$ \\
\hline
\end{tabular}

As shown in table (2), the IQ range was 92-98\% with Mean \pm SD (94.2 \pm 1.8$)$. The SSI score range was (20-33) with Mean \pm SD $(25.7 \pm 4.5)$. There were 10 children
$(33.3 \%)$ who were mild, 14 children $(46.7 \%)$ who were moderate and 6 children (20\%) who were severe degree of stuttering (Diagram 2).

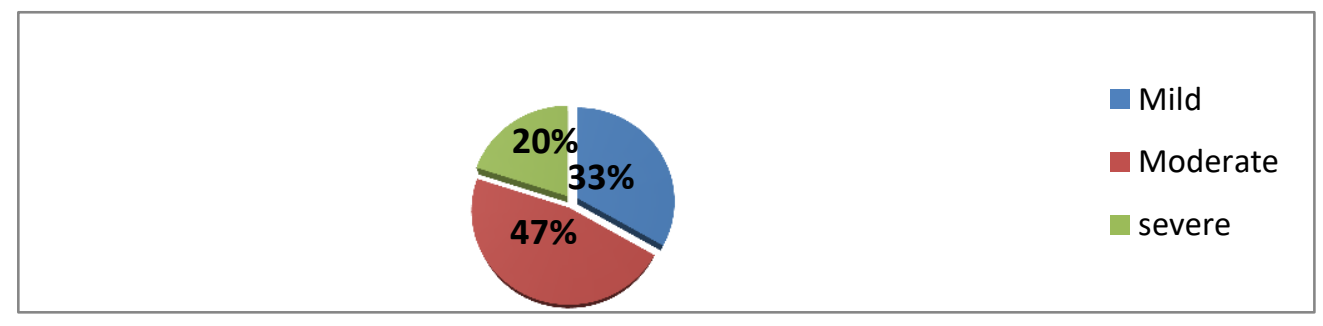

Diagram (2): Distribution of SSI degree in the study group

Table (3): Comparisons between different grades of SSI regarding chronological age, gender and IQ scores

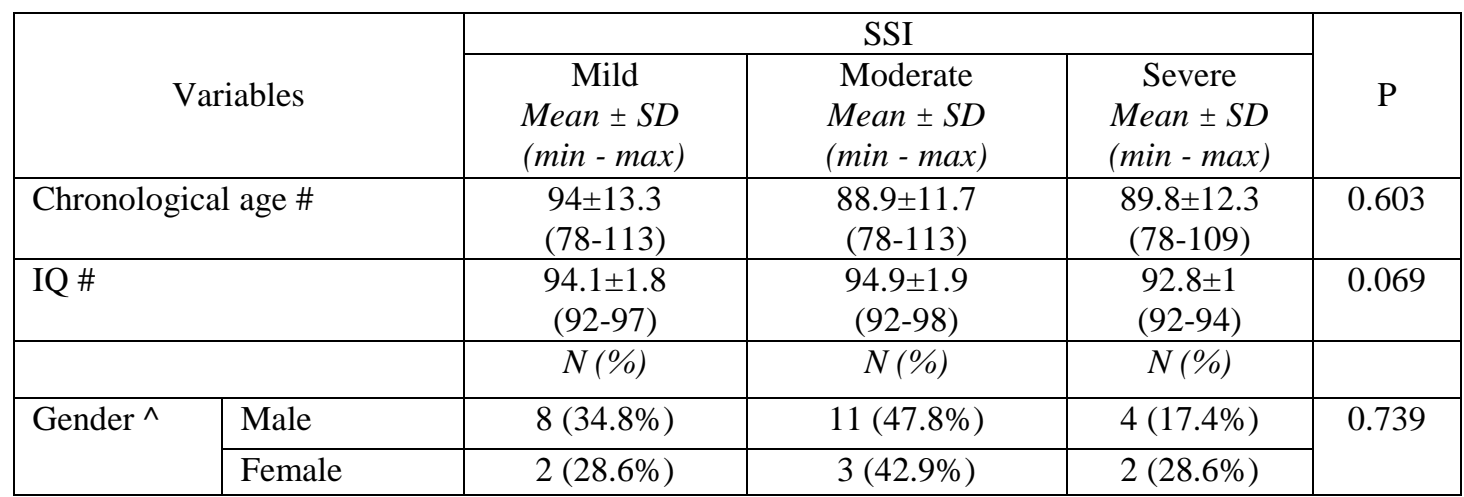

(\#) ANOVA test, $\left({ }^{\wedge}\right)$ fisher exact test $\quad$ P-value is significant $<0.05$

As shown in table (3), there were no statistically significant differences between different grades of SSI as regards chronological age, gender and IQ. 
Table (4): Difference between SSI scores in males and females

\begin{tabular}{|l|c|c|c|c|}
\hline & $\begin{array}{c}\text { Males } \\
\text { Mean } \pm \text { SD }\end{array}$ & $\begin{array}{c}\text { Females } \\
\text { Mean } \pm \text { SD }\end{array}$ & T-value & $\begin{array}{c}\text { P-value and } \\
\text { Significance }\end{array}$ \\
\hline SSI score & $25.3 \pm 5$ & $26.9 \pm 4$ & 0.803 & 0.43 (NS) \\
\hline
\end{tabular}

Table (4) showed that mean scores for males in our studied group for SSI score was 25.3 with $\mathrm{SD} \pm 5$ while that for females was 26.9 with \pm 4 SD. There were no statistically significant differences between SSI scores in male and female (P-value=0.43) (Diagram 3).

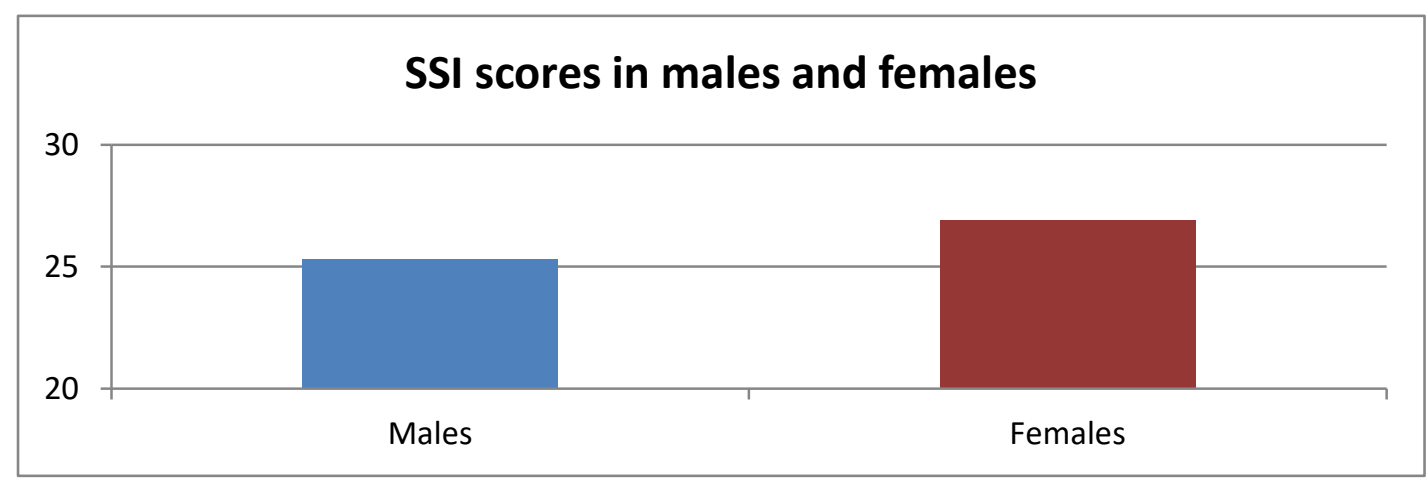

Diagram (3): SSI Scores in males and females

Table (5): Differences of SSI score among the three age groups

\begin{tabular}{|l|c|c|c|}
\hline & Age (6y 6m-7y 5m) & Age (7y 6m-8y 5m) & Age (8y 6m-9y 5m) \\
\hline Mean SSI score & $25.8 \pm 4$ & $26.0 \pm 3$ & $25.3 \pm 5$ \\
\hline F-Value* & \multicolumn{3}{|c|}{0.05} \\
\hline P-value and Significance & \multicolumn{3}{|c|}{05 (Non-significant) } \\
\hline
\end{tabular}

*ANOVA test

As shown in table (5), the differences of SSI scores among the three age groups were non-statistically significant $(\mathrm{P}$-value $=0.95)($ Diagram 4).

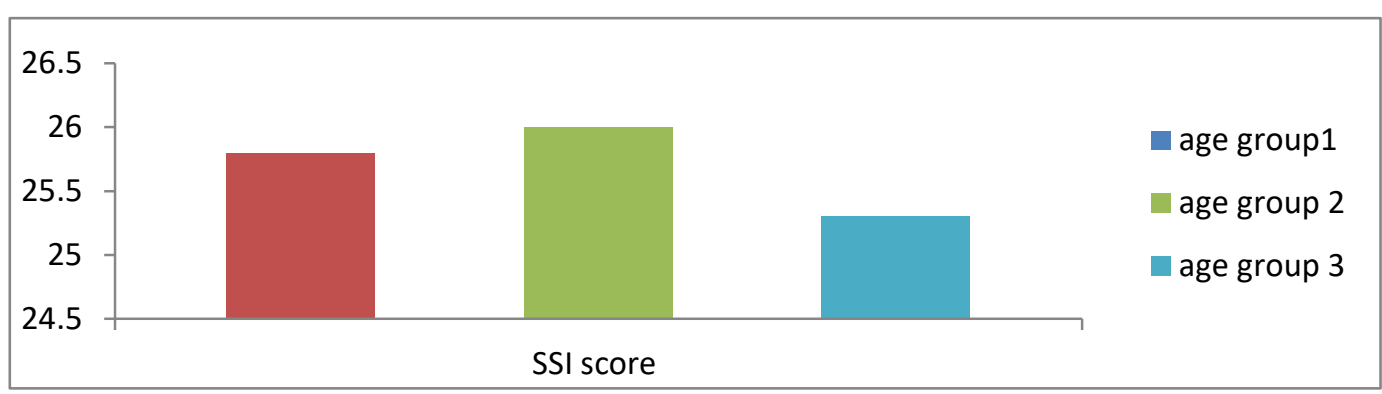

Diagram (4): Differences of SSI score among the three age groups

Table (6): Correlations between SSI and age and IQ in the whole group and in each of males and females:

\begin{tabular}{|c|c|c|c|c|c|c|c|c|}
\hline \multicolumn{3}{|c|}{$\begin{array}{c}\text { Males and females } \\
(\mathrm{N}=30)\end{array}$} & \multicolumn{3}{|c|}{$\begin{array}{c}\text { Males } \\
(\mathrm{N}=\mathbf{2 3})\end{array}$} & \multicolumn{3}{|c|}{$\begin{array}{c}\text { Females } \\
(\mathbf{N}=7)\end{array}$} \\
\hline & $\begin{array}{c}\text { Age } \\
91 \pm 12\end{array}$ & $\begin{array}{c}\text { IQ } \\
94.2 \pm 1.8 \\
\end{array}$ & & $\begin{array}{c}\text { Age } \\
92 \pm 13\end{array}$ & $\begin{array}{c}\text { IQ } \\
94.7 \pm 1.2 \\
\end{array}$ & & $\begin{array}{c}\text { Age } \\
87 \pm 8\end{array}$ & $\begin{array}{c}\text { IQ } \\
92.7 \pm 1.0\end{array}$ \\
\hline SSI score & $r=-0.07$ & $r=-0.29$ & SSI score & $r=0.04$ & $\mathrm{r}=-0.29$ & SSI score & $r=-0.56$ & $r=-0.012$ \\
\hline $25.7 \pm 4.5$ & (NS) & (NS) & $25.3 \pm 4.5$ & (NS) & (NS) & $26.9 \pm 4.3$ & (NS) & (NS) \\
\hline
\end{tabular}


Table (6) showed that there were negative correlations between SSI scores and age of the studied group as a whole $(\mathrm{r}=$ 0.07 ), but not statistically significant. There was positive correlation between the age of males and SSI score $(r=0.04)$. There was negative correlation between the age of females and SSI score $(r=-0.56)$, both not reaching significant levels.

The correlations between IQ and SSI scores for the main group as well as both male and female groups were negative with no statistically significant levels $(r=-0.29$, $0.29,-0.012$, respectively).

\section{DISCUSSION:}

Measuring the severity of stuttering symptom is an important tool in assessing success and efficacy of intervention. Phoniatricians reported different methods for assessing stuttering severity. Some of these methods are quantitative and others are qualitative $^{(22)}$.

Most clinicians rate stuttering severity quantitatively by counting the number of stuttered moments per unit time, average duration of the stuttered moment and tension accompanying the stuttered moments (associated movements, eye contact, difficult blocks...etc.).

Other clinicians use the stuttering severity index. It is a quantitative useful tool that proves its reliability and validity in estimating the stuttering severity in relation to the speech behaviors, but it may pause some challenges. Most of such measures focus on the measurable part of the problem and namely what is seen and heard of the symptom by the examiner. This is only the top of iceberg. The hidden associated feelings cannot be readily observed nor measured by the proposed index. It missed to assess the stutter's attitudes towards their stuttering, or the covert symptoms of stuttering.
Sheehan ${ }^{(23)}$ linked stuttering to an iceberg, with visible overt speech symptoms above the water representing the dysfluent speech, and the predominate aspects of the disorder representing the secondary behaviors (covert symptoms) that remain invisible to the observer under the water. These secondary behaviors include physical involuntary movements, interjections, together with feelings and thoughts of frustration, anxiety, anger, and expectation of difficulty in talking, which lead to avoidance behavior ${ }^{(24)}$.

Van Riper's equation represents qualitative description measure of the reaction to the symptom. Van Riper's equation:

Stuttering Severity $=\frac{\mathrm{PFAGH}+\mathrm{SF}+\mathrm{WF}+\mathrm{CS}}{M+F}$

$\mathrm{P}=$ Penalty, $\mathrm{F}=$ Fear, $\mathrm{A}=$ Anxiety, $\mathrm{G}=$ Guilt, $\mathrm{H}=$ Hostility, $\mathrm{SF}=$ Situation Fear, $\mathrm{WF}=$ Word Fear, $\mathrm{CS}=$ Communication stress, $\mathrm{M}=$ morale, $\mathrm{F}=$ fluency.

The reaction to the symptom is in the form of associated movements, struggle (location, degree and permanency), eye contact, associated feelings, approach avoidance conflict and associated physiological changes (perspiration, flusing, tachycardia).

Coming to assessment of these reactive symptoms, there are questionnaires for parents/children that ask direct questions about fears, avoidance, situations and relationships ${ }^{(25)}$. Also, there are many unstandardized attitude assessments tests, in addition to the psychological investigations. Besides, these different methods, neither of them is conclusive because stutterers differ in their reactions to stuttering. Most of them could anticipate difficult speech situations and feared words either by avoidance or restricting their speech output up to limiting their social relations ${ }^{(\mathbf{2 6})}$.

Furthermore, one of the most useful 
ways of analyzing patient's stuttering is to ask him/her to draw his/her own iceberg and to decide by himself/herself the relative proportion of the overt and covert symptoms of his/her stuttering. This is not applicable when dealing with a young CWS, because they barely recognize their problem and only their parents are the complainers. Moreover, parents of CWS became frustrated by the overt symptoms in the speech of their child, without considering the importance of the covert symptoms ${ }^{(23)}$.

Another measure in determining the severity of stuttering in children is Bloodstein classification (BLS). Bloodstein ${ }^{(27)}$ classified stuttering severity upon the child's awareness, sensitization (fears), avoidance and struggle. Bloodstein I: The child was unaware of his/her stuttering symptoms. Bloodstein II: The child is aware, but $\mathrm{s} / \mathrm{he}$ is not annoyed and has little or no concern about his stuttering. There is no avoidance of social and speech situations. Bloodstein III: The child is aware, annoyed, sensitized, partial avoidance and no struggle. Bloodstein IV: The child is fully aware and suffering, sensitized (Feared words, sounds and situations), systematic avoidance of the speech situation, struggle.

In our study, we used the SSI which is an objective, valid, reliable measure that rates the stuttering severity. It gives an index which represents the frequency and the rate of speech dysfluencies, as well as the concomitant physical reaction associated with these speech dysfluencies.

Choosing the age range between 6.5 to 9.5 years was in order to be sure of excluding the normal dysfluency that would be present at the age of less than 6.5 years.

In our study, results showed that in general, there was a negative correlation between SSI scores and age of the studied group, though statistically non-significant. This is similar to a study by Khodeir ${ }^{(28)}$ who found a significant inverse relation between the stuttering severity by SSI and the chronological age of the participated children $(\mathrm{r}=-0.569, \mathrm{p}<0.01)$. This indicates that speech dysfluencies counted by SSI decreases as the child's age increases. This may denote that as the child grows up, he/she becomes more mature and more aware to his/her speech problem and more capable of controlling or modifying it by alternative strategies, so as not to be apparent. Khodeir's study was applied on an age range of 5-9 years and 9 months which may account for more significant correlation within her study range.

The inverse relation between stuttering and age accounts for the high rate of spontaneous recovery for cases which were diagnosed during childhood. Longitudinal studies have reported recovery rates of $65 \%$ in the age range two to five years ten months ${ }^{(29)}, 74 \%$ in the age range two to four years 11 months ${ }^{(30)}$ and $79 \%$ in the age range two to 16 years $^{(31)}$. Recovery after teenage is rare $^{(31)}$. Based on these recovery statistics, at least $20 \%$ of children who begin to stutter will persist. One fifth of the $5 \%$ of cases in the pre-school population corresponds with the figure of $1 \%$ who stutter in the adult population $^{(32)}$.

The correlations between IQ and SSI scores for the main group as well as both male and female groups were negative with no statistically significant levels. This means that SS tends to decrease as cognitive abilities increase. Our results are based upon a selective category of stutterers who are all within an average range of intelligence. The negative (though non-significant correlation) between SS and IQ indicates that high cognitive abilities are needed to mask the dysfluency manifestations. Higher IQ levels may also point to a better prognosis for recovery.

Although there was no significant difference between SSI scores in males and females, yet the mean values in females $(26.9 \pm 4)$ were slightly higher than those of 
males $(25.3 \pm 5)$.

In our study, male percentage was $77 \%$ while female percentage was $23 \%$ making a ratio of 3.2: 1 which agree with the same ratio as mentioned by Kotby et al. ${ }^{(22)}$. Also, Howell et al. ${ }^{(6)}$ found the higher ratio in males than females (about 5.3:1). However, there was no statistically significant difference between SSI scores in males and females.

Gender as being a male is considered a precipitating factor to acquire stuttering ${ }^{(33)}$. Male predominance is due to delayed myelination of cortical area related to speech and language in male children in comparison to female ones /or may be due to inherent difference in the feedback relationship between hearing and speech for males and females, so delayed auditory feedback (DAF) disrupts the fluency of males more than females. In addition, females require longer delay times to induce disruption in their speech. The difference may also be due to the difference in the way that parents perceived, evaluated and reacted to stuttering of boys in contrast to that of girls /or slow acquisition of language in boys and their greatest tendency to articulatory errors and reading problems or/and less stable neuromuscular control over the speech apparatus in males at least during the early years of life ${ }^{(9)}$.

Finally, stuttering will remain a perplexing disorder and assessing its severity is a matter of clinician's clinical experience. Taking in considerations that there are a number of factors that may play a role in increasing the risk of developing the disorder and affect its severity.

\section{Conclusion:}

In the age range of 6.5 to 9.5 years, the male to female ratio of stuttering was 3.2:1. Speech dysfluencies as measured by SSI tends to decrease as the child's age increases and as IQ level increases within the average category of IQ. However, such relations are not statistically significant.

\section{REFERENCES:}

1. Coleman, C. (2013): SIGnatures: Widening the treatment circle: Special Interest Group 4, Fluency and Fluency Disorders. The American Speech-Language-Hearing Association Leader; 18(2): 54-56.

2. Gilman, J. (2012): Disability or identity? Stuttering, employment discrimination, and the right to speak differently at work. BrooklynLaw Review; 77(3), 317.

3. Manson, H. (2000): Childhood stuttering. Incidence and development. Journal of Fluency Disorders; 25(1):47-57.

4. Yairi, E., and Ambrose, N. (2005): Early childhood stuttering. Austin, TX: Pro-Ed.

5. Reilly, S., Onslow, M., Packman, A., Wake, M., Bavin, E. L., Prior, M., and Ukoumunne, O. C. (2009): Predicting stuttering onset by the age of 3 years: A prospective, community cohort study. Pediatrics; 123(1), 270-277.

6. Howell, P., Davis, S., and Williams, R. (2008): Late childhood stuttering. Journal of Speech, Language, and Hearing Research; 51(3), 669- 687.

7. Van Borsel, J., Brepoels, M., and De Coene, J. (2011): Stuttering, attractiveness and romantic relationships: The perception of adolescents and young adults. Journal of Fluency Disorders; 36(1), 41-50.

8. Ramig, P. and Dodge, D. (2009): The child and adolescent stuttering treatment and activity resource guide (2nd edition). Clifton, N.Y: Delmar.

9. Ward, D. (2006): Stuttering and cluttering frameworks for understanding and treatment. New York: Psychology Press; (1), 11-18.

10. Zhang, J., and Kalinowski, J. (2012): Culture and listeners' gaze responses to stuttering. International Journal of Language \& Communication Disorders; 47(4), 388-397.

11. Abdalla, F., and Al-Saddah, A. (2009): 
Stuttering and teachers in Kuwait: The story so far. In 12th International Stuttering Awareness Day Online Conference; (30), 2010.

12. Yaruss, J. S. (2010): Assessing quality of life in stuttering treatment outcomes research. Journal of Fluency Disorders; 35(3), 190-202.

13. Bleek, B., Reuter, M., Yaruss, J. S., Cook, S., Faber, J., and Montag, C. (2012): Relationships between personality characteristics of people who stutter and the impact of stuttering on everyday life. Journal of Fluency Disorders; 37(4), 325333.

14. Freud, D., Kichin-Brin, M., EzratiVinacour, R., Roziner, I., and Amir, O. (2017): The relationship between the experience of stuttering and demographic characteristics of adults who stutter. Journal of Fluency Disorders; 52, 53-63.

15. Yairi, E., and Ambrose, N. (2013): Epidemiology of stuttering: 21st century advances. Journal of Fluency Disorders; 38(2), 66-87.

16. Craig A, Hancock $K$, Tran $Y$ and Craig $M$ (2003): Anxiety levels in people who stutter: A randomized population study. Journal of Speech, Language, and Hearing Research; 46(5): 1197-1206.

17. Abou El Oyoun, A. (2000): epidemiological study of communicative disorders in Upper Egypt. Unpublished MD thesis in Phoniatric Unit, Faculty of Medicine, Ain Shams University.

18. Abou Ella, M., Saleh, M.,Habil, I., Mohammed El Sawy, M., and El Assal, L.(2015): Prevalence of stuttering in primary school children in Cairo-Egypt. International Journal of Speech-Language Pathology; 17(4): 367-372.

19. De Nil, L. (1999): Stuttering: A neurophysiological perspective. Stuttering research and practice: Bridging the gap; 85102.

20. Kotby, M., Youssef, M. and Refaie, N. (2015): Fluency disorders. In M.N. Kotby (Ed.). Disorders of Speech and Swallowing for Phoniatrics and Communication Disorders. A Publication of the Egyptian Society of Phoniatrics and Logopedics. El Hariry Print, Cairo, Egypt.

21. Rifaie, N. (1999): Arabicization and Standardization of the Stuttering Severity Index (S.S.I.) on the Arabic environment. Ain Shams Medical Journal; 50: 75- 79.

22. Melika, L. (1998): Stanford Binnet Intelligence Scale (4th Arabic version). Second Edition. Victor Kiorlos Publishing, Cairo.

23. Sheehan, J. G. (1975): Conflict theory and avoidance-reduction therapy. In Stuttering: A second symposium. New York: Harper and Row; 97-198

24. Etchell, A.C., Johnson, B.W. and Sowman, P.F. (2014): Behavioral and multimodal neuroimaging evidence for a deficit in brain timing networks in stuttering: a hypothesis and theory. Frontiers in Human Neuroscience; 8, 467.

25. Guitar, B. (2006): Stuttering, An Integrated Approach to its Nature and Treatment, Third Edition, Lippincott Williams and Wilkins, Philadelphia, PA.

26. Bloodstein, o., and Ratner, N. B. (2008): A Handbook of Stuttering, sixth ed., Thomson Delmar Learning, New York, 2008.

27. Bloodstein, O. (1969): A handbook on stuttering. National Eater Seal Society for Crippled children and adults. Chicago, Illinois.

28. Khodeir, M. S. (2019): Exploring stuttering severity in the Egyptian Arabic speaking children who stutter: A correlation study of Bloodstein classification of stuttering severity and the stuttering severity instrument for children and Adults-Arabic Version. International Journal of Pediatric Otorhinolaryngology; 125, 38-43.

29. Ryan, B. P. (2001): A longitudinal study of articulation, language, rate, and fluency of 22 preschool children who stutter. Journal of Fluency Disorders; 26(2), 107-127.

30. Yairi, E., and Ambrose, N. G. (1999): Early childhood stuttering I: Persistency and recovery rates. Journal of Speech, 


\section{Aya Sayed Ahmed Nasr, et al.,}

Language, and Hearing Research; 42(5), 1097-1112.

31. Andrews, G. and Harris, M. (1964): The Syndrome of Stuttering: Clinics in Developmental Medicine, No. 17. London: William Heineman Medical Books Ltd.

32. Bloodstein, O. (1995): A Handbook on stuttering (5th ed.). San Diego, CA: Singular Publishing Group.

33. Andrews, G., Morris-Yates, A., Howie, P., and Martin, N. (1991): Genetic factors in stuttering confirmed. Archives of General Psychiatry; 48(11), 1034-1035.

العلاقة بين شدة التلعثم والخصائص الايموغرافية للأطفال الذين يتلثثمون والذين تتراوح اعمارهم بين آسنوات ونصف والفي

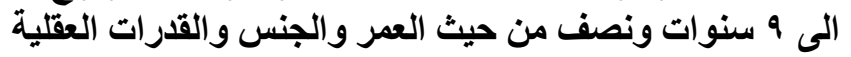

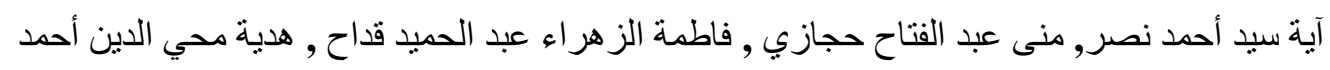

القسم: وحدة أمر اض التخاطب ـ قسم الأنف و الأذن و الحنجرة ـ كلية الطب ـ جامعة عين شمس, جمهورية مصر العربية, القاهرة

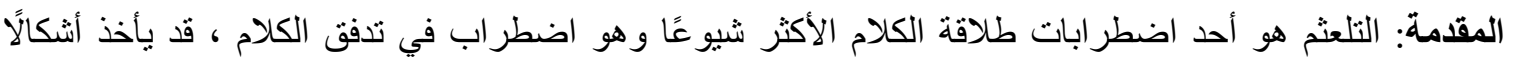

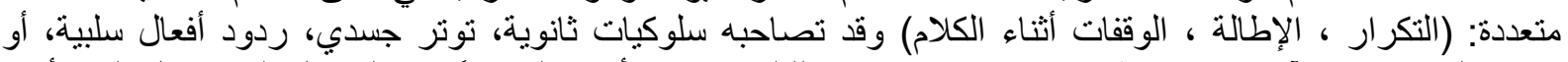

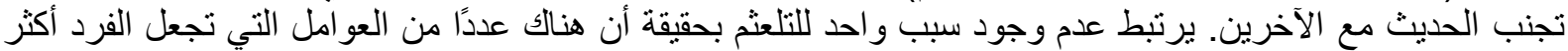
عرضة للإصابة بهذا الاضطر اب. يمثل العمر الزمني و الجنس و القدرات العقلية عو امل خطر مهمة للتلعثم وقد تلعب أيضًا

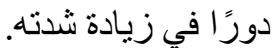

هدف الاراسة: تهدف هذه الدراسة إلى فحص العلاقة بين شدة التلعثم في الاطفال الذين يتلعثمون والعمر والجن الجنس و القدرات العقلية. هذه العو امل مهمة للتقييم الأولي للتلعثم وقد تكون مفيدة لتحديد التندخل المناسب.

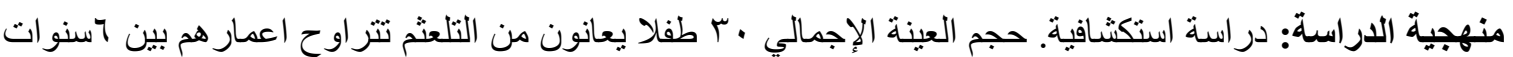

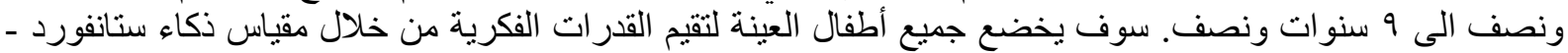

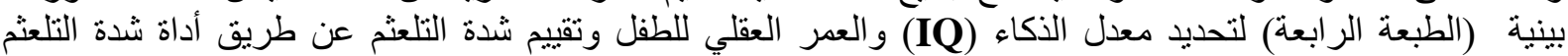
للأطفال و الكبار - النسخة العربية.

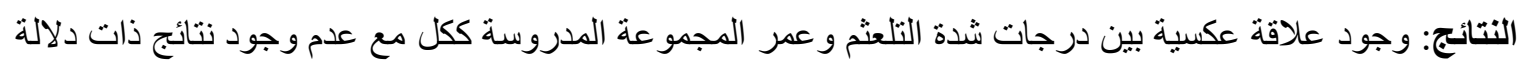

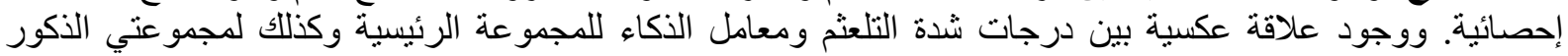

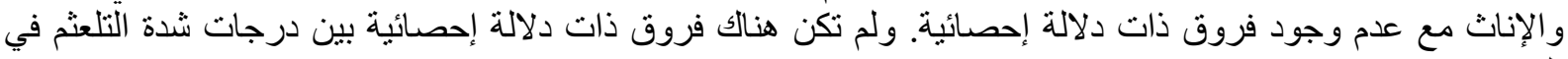
الذكور و الإناث.

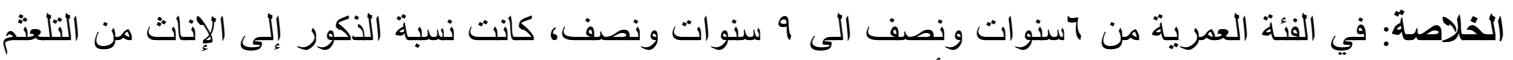

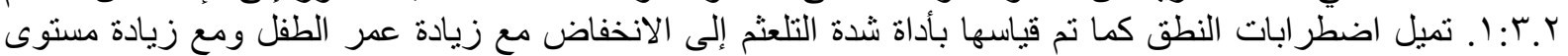
الذكاء ضمن فئة متوسط الذكاء. ومع ذللك ، فإن هذه العلاقات ليست ذات الئ دلالة إحصائية.

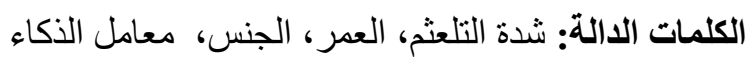

